\title{
Perceptions of health managers and professionals about mental health and primary care integration in Rio de Janeiro: a mixed methods study
}

Karen Athié ${ }^{*}$, Alice Lopes do Amaral Menezes², Angela Machado da Silva², Monica Campos³, Pedro Gabriel Delgado ${ }^{4}$, Sandra Fortes ${ }^{2}$ and Christopher Dowrick ${ }^{5}$

\begin{abstract}
Background: Community-based primary mental health care is recommended in low and middle-income countries. The Brazilian Health System has been restructuring primary care by expanding its Family Health Strategy. Due to mental health problems, psychosocial vulnerability and accessibility, Matrix Support teams are being set up to broaden the professional scope of primary care. This paper aims to analyse the perceptions of health professionals and managers about the integration of primary care and mental health.

Method: In this mixed-method study 18 health managers and 24 professionals were interviewed from different primary and mental health care services in Rio de Janeiro. A semi-structured survey was conducted with 185 closed questions ranging from 1 to 5 and one open-ended question, to evaluate: access, gateway, trust, family focus, primary mental health interventions, mental health records, mental health problems, team collaboration, integration with community resources and primary mental health education. Two comparisons were made: health managers and professionals' (Mann-Whitney non-parametric test) and health managers' perceptions (Kruskall-Wallis non parametric-test) in 4 service designs (General Traditional Outpatients, Mental Health Specialised Outpatients, Psychosocial Community Centre and Family Health Strategy)(SPSS version 17.0). Qualitative data were subjected to Framework Analysis.

Results: Firstly, health managers and professionals' perceptions converged in all components, except the health record system. Secondly, managers' perceptions in traditional services contrasted with managers' perceptions in community-based services in components such as mental health interventions and team collaboration, and converged in gateway, trust, record system and primary mental health education. Qualitative data revealed an acceptance of mental health and primary care integration, but a lack of communication between institutions. The Mixed Method demonstrated that interviewees consider mental health and primary care integration as a requirement of the system, while their perceptions and the model of work produced by the institutional culture are inextricably linked.

Conclusion: There is a gap between health managers' and professionals' understanding of community-based primary mental health care. The integration of different processes of work entails both rethinking workforce actions and institutional support to help make changes.
\end{abstract}

Keywords: Mental health, Primary care, Collaborative care, Mental health matrix support, Integration, LAMIC, Mixed methods, MHGAP, Public health, Implementation science

\footnotetext{
* Correspondence: karensathie@gmail.com

'Programa de Pós Graduação em Ciências Médicas/ Faculdade de Ciências

Médicas, Universidade do Estado do Rio de Janeiro, Rio de Janeiro, Brazil

Full list of author information is available at the end of the article
} 


\section{Background}

Mental health problems [1] are a challenge to public health systems, especially in low and middle-income countries (LAMIC) [2, 3]. Studies [4, 5] have demonstrated that they are associated with important economic and social problems regarding global health and the impact of sustainable development [6]. Primary health care has been understood as the basis for reducing the gap between population needs and care offers, especially delivered through primary care and communitarian actions [7, 8]. Integration and delivery of primary mental health care are of increasing importance for the achievement of these goals.

The literature review on studies about primary care and mental health integration covers a broad scope including Human Rights [9], Welfare State organisation [10], the integration of different work processes [11-13], human resources training [14], access [15], common mental disorders $[16,17]$, medication [18] and psychosocial interventions [17]. Integrating health actions is complex and health managers and care professionals need more than just to agree to share the same physical place in order to work together $[19,20]$. Therefore, this complex practice emphasises how important it is to prepare human resources to deliver mental health care in the community [1] and to organise integrated work processes, both of which are considered challenges to this integration [21].

Furthermore, little is known about professionals' perceptions regarding integrated care. A single study in Latin America that focused on health professionals' [22] opinions, suggests that managers' and health professionals' opinions are based on past experience, expectations, definitions of quality of care and power relationships between health professionals. A second point is a wide-ranging and confused terminology concerning primary mental health, which can also be a barrier to defining collaboration processes between different workers [23]; although the words used to define them can be very similar, interpretations on how to apply them can vary very often. the way to interpret and apply them is variable.

Additionally, as integrated care is an international recommendation requiring changes in the organisation of health systems, especially in LAMIC, these changes are being made all over the world, including Brazil. The SUS (the Brazilian National Health Service, or literally the Unified Health System $)^{1}$, created with the new constitution in 1988 during the country's redemocratisation process, is based on the tenets of universal, integral and equal rights of access to health. Based on these principles, changes to strengthen community-based primary care services have been implemented since the 1990s. In Brazil, traditionally, primary care was organised into General Traditional Outpatient services (GTO). These units covered large geographical areas, with 100,000 inhabitants, involving professionals from different medical backgrounds in basic specialities. After 1994, this primary care model started to change progressively to the Family Health Strategy (FHS) model, where multidisciplinary teams are responsible for 3500 people (not necessarily patients) living in a community-ascribed area [24] (see Table 1).

This change in Brazilian Primary Care, delivering health services in communities instead of waiting for populations' demands, brought about important improvements in public health indicators, such as an increase in the detection of neglected tropical diseases, and reduced health disparities and child mortality. The communitarian basis revealed a high prevalence of mental health problems in the ascribed population, which is associated with psychosocial problems, lower quality of life and clinical co-morbidities [25, 26]. Due to SUS' equal tenet, FHS teams have been initially implemented in low-income areas where they must deal with problems such as domestic violence and drug dealers, as well as treating diseases such as diabetes, HIV and hypertension.

In parallel, also since the 90's, mental health services started to undergo reform shifting from long-term Psychiatric Hospital beds to Mental Health Psychosocial Community Centres (PCC). This is the target of the Brazilian Psychiatric Reform [27], which set out the Brazilian Mental Health Policy in 2001. PCC were created to care for those patients with severe mental health problems within a population of 100,000 inhabitants. For patients with less severe mental disorders, but still in need of specialised mental health care, there are Mental Health Outpatient Services (MHOS). Their integration is by referral and counter-referral processes (Table 1). Moreover, in view of the stigma surrounding mental health issues and the vulnerability of the lowincome population covered by FHS, a local model of collaborative care was developed, based on Mental Health Matrix Support teams (MHMS). These teams help FHS teams to deal with psychosocial problems and common mental disorders. Collaborative care entails continuing education, which involves enabling capacity building of the FHS teams while MHMS teams assist them organising the delivery of mental health care in communities as well as helping them in the treatment of traditional primary mental health problems, such as medically unexplained symptoms, psychosomatic problems and common mental disorders (see Fig. 1).

One of the main problems faced by SUS is the integration of different service levels, which aims to increase access to the most vulnerable population living in very low development conditions [24], and narrow the gap between mental health needs and treatment offer. Therefore, the Brazilian Mental Health Service is divided 
Table 1 SUS primary care and mental health services

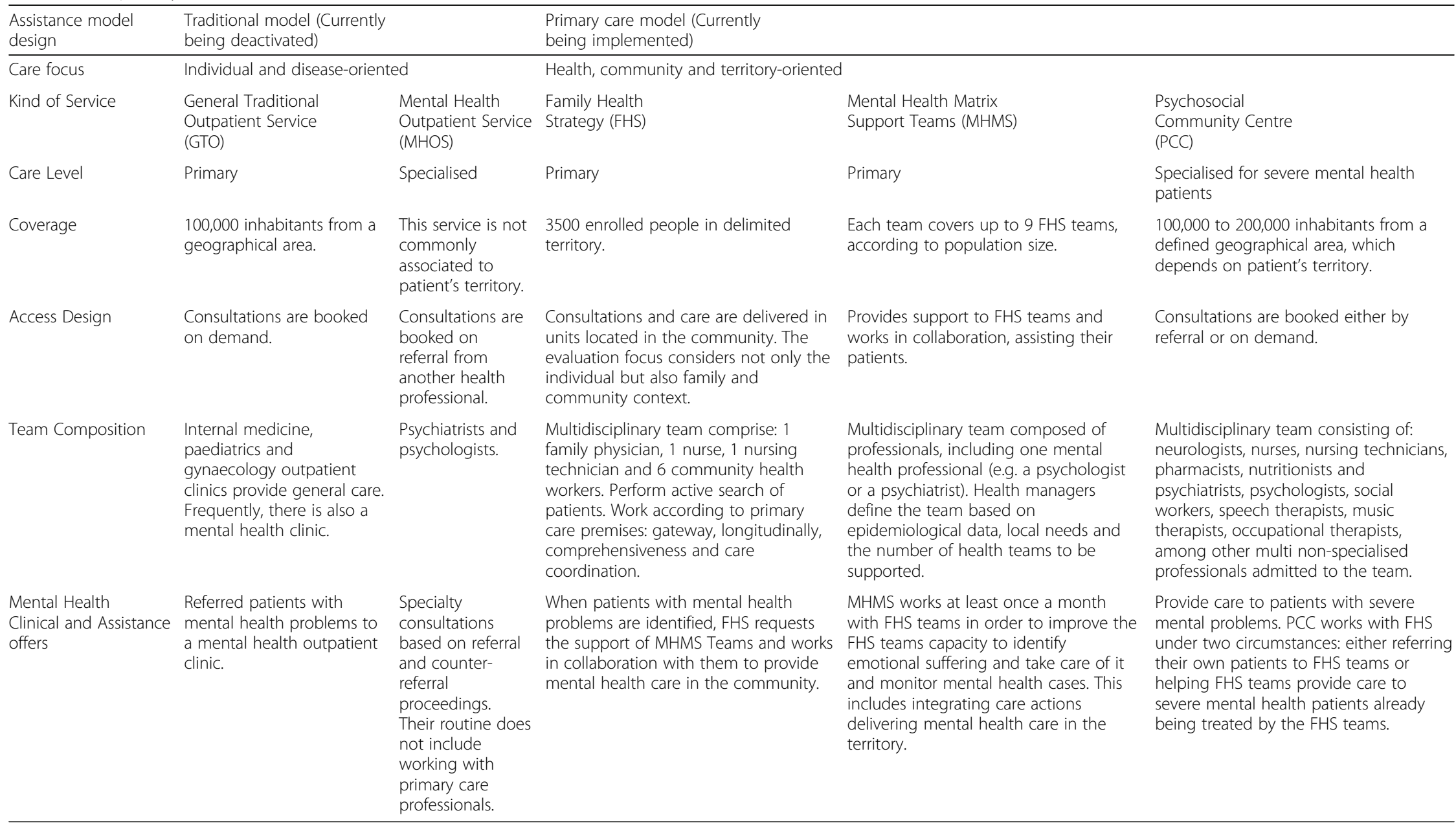




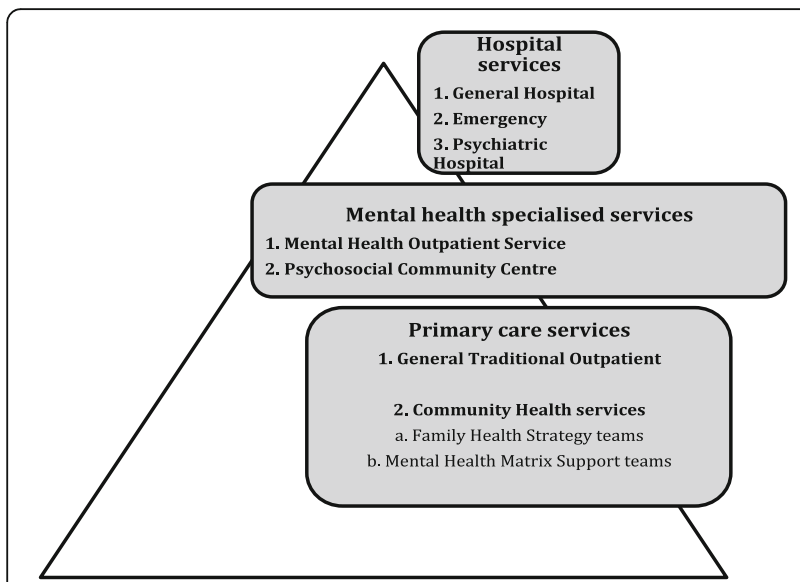

Fig. 1 The SUS services including mental health offers

into three levels: primary care services, specialised outpatient units and hospitals, as shown in Fig. 1.

Rio de Janeiro City has been an important example of this process, with a shift from General Traditional Outpatients to FHS teams, increasing their coverage from $3.5 \%$ in 2008 to $40 \%$ in 2012 [28, 29], mainly in poor and violent inner-city communities [30] (Fig. 2).

The context includes important social contrasts, notably between favelas (slums) and middle and upper-class homes, which coexist in the same neighbourhood [31, 32]. Thus, the Human Development Index varies from high to very low (e.g. 0.97 in Gávea neighbourhood vs. 0.25 in Realengo) [33-36]. There are stark differences even in poor areas. For example, in total, there are about 800 favelas and their social development index ranges from 0.63 (medium) to 0.25 (very low). Over 750 of those are below 0.59 (low human development). Additionally, some favelas, often controlled by drug dealers [37], tend to be violent in spite of political and military actions implemented since 2010.

Preferentially, primary care units have been located in places accessible to these vulnerable communities, which in Rio are usually found on the hillsides next to middleclass neighbourhoods.

Hence, in 2008, considering collaborative care experiences from the United Kingdom and other countries [38-40], a research group ${ }^{2}$ on mental health in primary care from the University of the State of Rio de Janeiro (UERJ) started to work with primary care teams in one of Rio de Janeiro's Health Districts, known as Programmatic Area 2.2, with 371,120 inhabitants.

Due to patients' problems such as anxiety, depression, post-traumatic stress and unexplained medical complaints, a group of researchers, professors, residents and health professionals undertook actions aimed at mental health and primary care professionals working together.

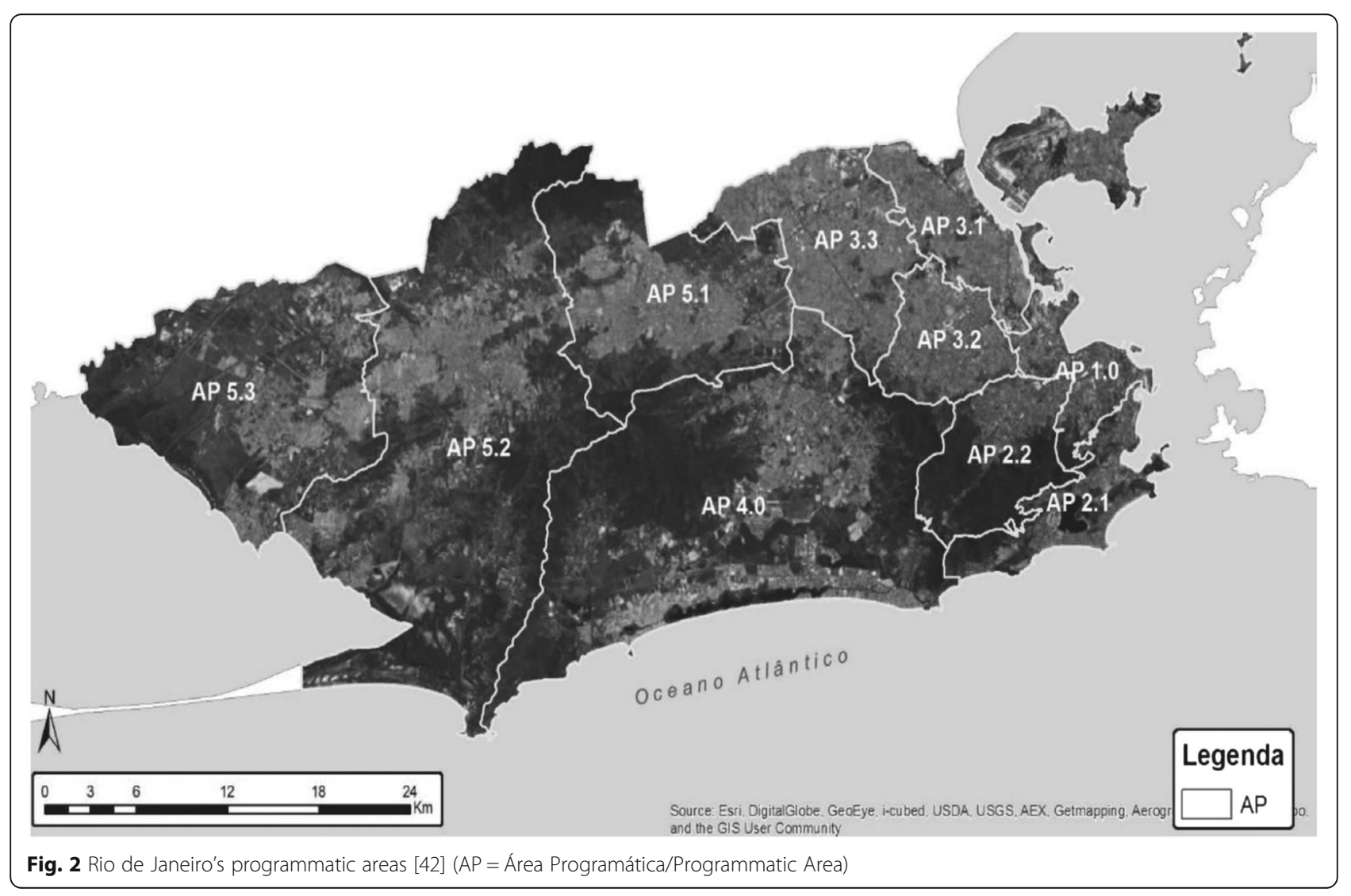


These actions were based on the integration of mental health and primary care in this part of Rio and included training primary mental health workers. Thus, a partnership involving the University of the State of Rio de Janeiro(UERJ) and the coordination staff of Programmatic Area 2.2 has fostered MHMS activities in the health units in this region with a view to integrating mental health teams and primary care.

These collaborative experiences between the local services and UERJ tested this integrated model of work (MHMS) while national deliberations (Law 154/2008) on an interdisciplinary collaborative care model for SUS were approved. The Matrix Support Teams, officially called NASF (Núcleo de Apoio a Saúde da Família), were created to work together with FHS in order to improve their capacity. So, the matrix support implemented in PA 2.2, at this historical moment, can be considered an innovation involving all primary care services, outpatient services and psychosocial community centres. When this research was carried out (between 2011 and 2013), PA 2.2 had not completely deployed the NASF team based on the national model references. This pioneer experience in PA 2.2 was important also to develop the first practical national recommendations about mental health matrix support for the NASFs, the Practical Guide to Primary Mental Health Care [41].

The purpose of this paper is to study health managers' and professionals' perceptions, in their different services, about the integration of mental health in primary care settings. The main goal is to analyse them and point out key messages related to planning, organisation and implementation of collaborative care to reduce the local mental health gap and foster continuity of care.

\section{Method}

\section{Design of the study}

This mixed-method cross-sectional study was developed to map different aspects of mental health and primary care integration from the perspective of health managers and health professionals. Thereby, considering them as potential supporters or stakeholders of the integration of mental health in primary care, this research has tackled three research issues. The quantitative study pointed out how they evaluate their health actions regarding primary mental health care references, and the qualitative one, as a necessary complement, explored their experience of MHMS.

The issues were:

- health managers' and professionals' perceptions about primary mental health care implementation in Rio in the period studied;

- the similarities and differences between health managers' and professionals' perceptions;

- prospects for Brazilian MHMS.

\section{Setting characteristics}

Geographical and socio-economic context in Rio de Janeiro's favelas

This study was conducted in Rio de Janeiro City, which is divided into ten Health Districts (Programmatic Areas) (Fig. 2) [42], all of them providing similar mental health and primary care services. This programmatic area (PA 2.2) has 371,120 inhabitants in 7 neighbourhoods: Alto da Boa Vista, Praça da Bandeira, Tijuca, Andaraí, Grajau, Maracanã and Vila Isabel. For public health management purposes, each neighbourhood is divided into micro-areas. Although the area's Human Development Index (HDI) is about 0.9, which is similar to rich countries, the region is marked by social contrasts. According to the last national census, monthly income ranged from \$ 61.12 to 3558.59 [34] (American dollars). The Social Development Index (SDI) verified that the highest rate is 0.7 in Maracanã (high development conditions) and the lowest is 0.54 in Praça da Bandeira (low development conditions). The favela population accounts for around 43,000 inhabitants. In the micro-areas of this study the ratio ranges from 0.55 (low) in Parque Vila Isabel to 0.48 (very low) in the Casa Branca Community. Moreover, 4 of the 37 Peacemaking Police Units are located in this region. Since 2010, these units have been deployed in Rio de Janeiro's favelas and other underprivileged areas with violence and drug dealing.

\section{SUS Primary Care and Mental Health Services Designs in Programmatic Area 2.2}

The survey was conducted with health professionals working in all primary care and mental health units in this region: General Traditional Outpatient Services $(\mathrm{GTO})(n=4)$, Mental Health Outpatient Services $($ MHOS $)(n=4)$, Psychosocial Community Centres (PCC) $(n=2)$, Family Health Strategy $(\mathrm{FHS})(n=8)$. In view of the complex makeup of the SUS (Fig. 1), with part of the services being deactivated and another part being implemented, some important aspects of these services must be highlighted, such as care focus, service status, care level, coverage, access design, team composition, principles of mental health clinical and assistance management (Table 1).

\section{Participants}

In this research all professionals involved in mental health matrix support activities in PA 2.2 were interviewed, including family health doctors and MHMS supporters, as well as all health unit managers in this area. Due to the moment of this new model's implementation in this area, the group concerned was still small. Thus, in total, all 42 people working with MHMS were interviewed (35 female and 7 male), covering all health managers ( 15 female and 3 male), general practitioners, psychologists and psychiatrists 
(20 female and 4 male), all involved in primary care and mental health integration in the territory studied.

Other FHS professionals, such as nurses and community health workers were excluded. The reasons were: firstly, during the period studied, MHMS activities were mainly between doctors and mental health professionals, and secondly, despite the relevance of other FHS professionals'opinions, this project had financial constraints and, consequently, nine more nurses and fifty-four Community Health Workers, who did not take active part in the mental health matrix support work, were not interviewed.

Among the 18 health managers we observed different professional backgrounds, namely: doctors (8), nurses (6), dentist (1), physiotherapist (1), social worker (1), psychologist (1) and of the 24 health professionals, there were General Practitioners (13), psychiatrists (4) and psychologists (7).

After obtaining approval from an official local district council and from the university's ethical committee, these professionals were invited either by email or phone and asked to participate voluntarily. All of them signed an informed written consent approved by the ethical committee. Each interview took approximately $90 \mathrm{~min}$; all of them were recorded.

\section{Data collection tool: creating an instrument to evaluate mental health and primary care integration}

A semi-structured questionnaire (see Additional file 1) was created to quantitatively evaluate these professionals' perceptions of their own services in relation to integration processes, followed by one open-ended question inquiring about positive and negative aspects of MHMS. To create this instrument, three other instruments were considered. The first is an international reference created to evaluate primary care services, The Primary Care Assessment TOOL [43, 44]; the second is the corresponding Brazilian version of the first, adapted to the Brazilian context and validated into Brazilian Portuguese [45]; the third is a questionnaire to evaluate Brazilian multidisciplinary teams [46].

The questionnaire, specially developed for evaluating primary care and mental health integration, comprised 185 questions, divided into different sections (Table 2). Alternatives were presented on a Likert scale ranging from 1 (none or never), 2 (almost never), 3(sometimes), 4 (almost always) to 5 (always). In the mental health problems section, which sought to identify how professionals observed specific mental health problems among patients coming into their units, the scale varied from 0 (no-one), 1 (low frequency), 2 (medium frequency), to 3 (high frequency). Besides the answer scale, the section about mental health interventions and integration with the community had space for freely stating examples. At the end of the survey, there was an open-ended question about positive and
Table 2 Description of questionnaire's sections

\begin{tabular}{|c|c|}
\hline Section & Objective \\
\hline General Information & $\begin{array}{l}\text { To map profession, function and } \\
\text { workplace. }\end{array}$ \\
\hline Access & $\begin{array}{l}\text { To map whether patients can access } \\
\text { services, medicines and consultations. }\end{array}$ \\
\hline Gateway & $\begin{array}{l}\text { To map the different services available } \\
\text { to patients in the unit }\end{array}$ \\
\hline Trust & $\begin{array}{l}\text { To map the relationship between patients } \\
\text { and health professionals, and patients and } \\
\text { units }\end{array}$ \\
\hline $\begin{array}{l}\text { Primary Mental Health } \\
\text { Interventions }\end{array}$ & To map psychosocial actions offered. \\
\hline $\begin{array}{l}\text { Primary Mental Health } \\
\text { Record }\end{array}$ & $\begin{array}{l}\text { To map if mental health interventions are } \\
\text { recorded in the Health Record System as } \\
\text { mental health interventions or primary } \\
\text { care interventions. }\end{array}$ \\
\hline $\begin{array}{l}\text { Collaboration between } \\
\text { Teams }\end{array}$ & $\begin{array}{l}\text { To map collaborative work with different } \\
\text { health teams and services as well as with } \\
\text { other institutions such as health services, } \\
\text { schools or community services. }\end{array}$ \\
\hline Mental Health Problems & $\begin{array}{l}\text { To map mental health problems treated } \\
\text { in the unit. }\end{array}$ \\
\hline Family Focus & To map family interventions. \\
\hline $\begin{array}{l}\text { Integration with Community } \\
\text { Resources }\end{array}$ & $\begin{array}{l}\text { To map institutional integration with } \\
\text { community resources. }\end{array}$ \\
\hline $\begin{array}{l}\text { Primary Mental Health } \\
\text { Education }\end{array}$ & $\begin{array}{l}\text { To map educational expectations regarding } \\
\text { mental health in primary care. }\end{array}$ \\
\hline $\begin{array}{l}\text { Positive and Negative } \\
\text { Aspects (Open-ended } \\
\text { question) }\end{array}$ & $\begin{array}{l}\text { To map positive and negative aspects of } \\
\text { primary care and mental health integration. }\end{array}$ \\
\hline
\end{tabular}

negative aspects of primary care and mental health integration, related to the previous 6 months.

\section{Pilot study of mental health and primary care integration instrument}

A pilot test was conducted in two stages. Firstly, undergraduate students training to work in primary mental care settings applied the questionnaire to verify language problems and the amount of time needed to answer each question. The problems were adjusted to improve the instrument, which was also discussed individually and collectively with mental health and primary care professionals and managers from other territories. Secondly, each of the three research applicants made one training interview with a health professional working outside PA 2.2.

\section{Periods of interviews}

The interviews occurred in two periods. Firstly, managers were interviewed from September 2011 to January 2012. The health professionals' interviews were collected from December 2012 to November 2013. From this group one GP did not participate as he was on 
holiday. Due to the lack of financial resources to cover researchers' interview fees, the second period was longer than planned.

\section{Alpha crombach}

In order to validate the questionnaire, Cronbach's Alpha was calculated, after concluding the managers' interviews, so that internal consistency could be evaluated. The internal consistency by section was: unacceptable for Access $(a=0.495)$; questionable for Gateway $(a=0.649)$ and Integration with Community Resources $(a=0.662)$; acceptable for Trust $(a=0.729)$, Collaboration between Teams $(a=0.764)$ and Mental Health Problems $(a=0.762)$; good for Family Focus $(a=0.852)$; and excellent for Primary Mental Health Interventions (0.909), Mental Health Interventions Record $(a=0.912)$ and Primary Mental Health Education $(a=0.882)$. The final result was 0.730 ( $p$-value 0.000$)$, which was considered acceptable [47-49].

\section{Analysis}

Analysis of the database involved two interpretative phases. First, while the quantitative analysis compared 1) health managers considering their design services and 2) health managers' and professionals' perceptions as a workforce, the qualitative analysis considered the whole group's perceptions about the advantages and disadvantages of MHMS. Secondly, to answer the three key issues about mental health and primary care integration, a framework was created to identify convergences and divergences between qualitative and quantitative results and associate them.

\section{Quantitative analysis}

Data were analysed with SPSS statistical software (version 17.0). The Mann-Whitney non-parametric test was used to compare health professionals' and managers' perceptions. The second comparison was to observe different types of primary care and mental health managers' perceptions. The Kruskall-Wallis non-parametric-test was used to compare managers' perceptions in 4 kinds of services (GTO, MHOS, PCC and FHS). Numerical data were calculated based on the number of answers to each section. The missing values were not excluded; they were replaced by mean values.

Considering each dimension studied, the hypotheses were:

Hypothesis 1 . Health managers and professionals diverge in their answers evaluating mental health and primary care integration.

Hypothesis 2. Managers from different services diverge in their answers evaluating mental health and primary care integration.

\section{Qualitative analysis}

Examination was based on framework analysis and thematic analysis methods.

Qualitative data encompassed all information that participants were asked to provide to complement or exemplify their answers to the quantitative survey questions. For instance: descriptions of resources; examples of mental health interventions not mentioned in the questionnaire; examples of collaboration between health services, education and community, and of integration with other services. Besides that, an open-ended question requested explanations about positive and negative aspects of mental health and primary care integration.

The content was described and organised according to the framework analysis method [50], which allowed for the comparison of positive and negative aspects. Firstly, content analysis enabled grouping of a large amount of text into categories. This analysis was processed using the same quantitative method dimensions (Table 2) as a filter. To interpret the data, interviews were repeatedly read and listened to and ideas about key aspects were noted down to develop initial codes as a thematic analysis. Next, they were linked according to their nature and contents to length and frequency of these perceptions [24, 51]. These codes helped to arrange the data into broader themes, which were revised. The discussion between three researchers processed the data into the most prominent ideas. These ideas were organised into three categories. Although this field of study is treated in interesting international studies [52, 53], this approach was chosen due to lack of past research in this field, where the growth of MHMS teams in SUS's structure is being progressively implemented in order to cover a country with more than 5000 municipalities. Thus, themes were developed inductively [54].

\section{Mixed method}

The integration $[55,56]$ of these two methods was arranged in a framework considering three key issues introduced at the beginning of the method section. Subsequently, qualitative and quantitative answers were compared to see if they converged or diverged. The analysis was conducted according to primary mental health care references [57].

\section{Results}

\section{Quantitative results}

Health Managers' and Professionals' perceptions

Given that health managers and professionals diverge, their perceptions about the results of different points evaluated in this study proved to be similar in most respects.

The group evaluated Access (2.9/5) worse than Gateway (3.5/5), which means that while about $60 \%$ of the population they are covering can have access to their 
services, once this population arrived at this offer this sample considered that people have more chances (70 \%) of starting a treatment. Trust (4.3/5) demonstrated that this group evaluated their relationship as positive with people that they take care of. Mental Health Interventions (2.8/5) highlighted that this sample does not consider that Mental Health interventions are offered to a percentage smaller than about $55 \%$ of their patient needs. Team Collaboration (3.3/5) showed that this group as a whole has a positive perception of their co-joint actions. However, their evaluation of the record system revealed different perceptions between the two groups included in this sample. While assistance professionals evaluated (2.4/5) that less than $50 \%$ of these recorders are adequate, health managers had a more positive view of this point, considering (3.3/5) about $70 \%$ of these recorders adequate. Mental Health Problems (1.6/4) highlighted that the perceptions of the interviewees were $40 \%$ between a low (1 to $30 \%$ ) and a medium (31 to $60 \%$ ) frequency of mental health problems in the patients treated in their units. Family Focus $(3.4 / 5)$ results showed that they usually work considering family problems in about $70 \%$ of cases. However, in Integration with Community Resources (2.6/5), they demonstrated that they work with these resources in about $50 \%$ of their needs. Concluding, Primary Mental Health Education (3.4/5) highlighted that continuing educational activities to prepare interviewees and their unit teams to work with primary mental health care is positive in $70 \%$ of the answers (Table 3 ).

\section{Managers' perceptions of service design}

Concerning the hypothesis that managers from services diverge in their evaluation of mental health and primary care integration in their own routine, the findings confirmed that units see things differently in this regard.

Access dimension $(p$-value $<5)$ highlighted that managers working in mental health outpatient services consider that only about $50 \%(2.4 / 5)$ of people that need their services have access to them. The other managers evaluated this higher, (in about $65 \%(3.2 / 5)$ of cases, people have access to their services). Managers perceived Gateway similarly: about $70 \%$ of patients $(3,6 / 5)$ are treated in these services when they have access to them. Trust (between patients and health professionals) was the best evaluated section (4.4/5), which means that these managers considered that their relationship with patients is good. In Mental Health Interventions ( $p$-value $<5)$, non-specialised $(\mathrm{GTO}=2.1$; FHS $=2.8)$ services evaluated their actions worse in terms of mental health activities than specialized services $(\mathrm{MHOS}=3.0$; $\mathrm{PCC}=3.8$ ); Record System was considered adequate in about $70 \%$ of cases $(3,3 / 5)$. In Collaboration between Teams, $\operatorname{GTO}(2,6 / 5)$ managers made a worse evaluation, followed by MHOS(3,3), FHS(3,6) and PCC(3,7). Mental Health Problems (1.5/4) highlighted that interviewees' perceptions were $37 \%$ between a low ( 1 to $30 \%$ ) and a medium ( 31 to $60 \%)$ frequency of mental health problems in the patients treated in their units. Family Focus is best evaluated in services based in communities. While $\operatorname{GTO}(2,3)$ and MHOS(2.8) evaluated that their offer has a Family Focus in less than $60 \%$ of their cases, PCC(4.0) and FHS(3.9) evaluated that they offer that in $80 \%$ of cases. Integration with Community Resources (2.7/5) are smaller than $60 \%$. To conclude, Primary Mental Health Education ( $p$-value $<5)$ is better evaluated in community-based services $(\mathrm{PCC}=4,7 ; \mathrm{FHS}=3,9)$, followed by $\operatorname{MHOS}(3.0 / 5)$ and $\mathrm{GTO}(2.3 / 5)$, which evaluated this point as very low.

Table 3 Comparing health managers'and professionals' perceptions

\begin{tabular}{|c|c|c|c|c|c|c|}
\hline \multirow{3}{*}{$\begin{array}{l}\text { Health Managers' and Professionals' } \\
\text { perceptions } \\
\text { Mann-Whitney non-parametric test (M-W) }\end{array}$} & \multicolumn{3}{|l|}{ Mean } & \multicolumn{3}{|c|}{ Std. deviation } \\
\hline & \multicolumn{3}{|c|}{ Health Managers and Professionals $(n=42)$} & \multicolumn{3}{|c|}{ Health Managers and Professionals AP } \\
\hline & Prof. $n=24$ & Man. $n=18$ & Total & Prof. & Man & Total \\
\hline Access & 2.9 & 3.0 & 2.9 & .64 & .43 & .55 \\
\hline Gateway & 3.5 & 3.6 & 3.5 & .71 & .74 & .72 \\
\hline Trust & 4.3 & 4.4 & 4.3 & .37 & .37 & .37 \\
\hline Mental Health Interventions & 2.8 & 2.8 & 2.8 & .38 & .63 & .50 \\
\hline $\begin{array}{l}\text { Is Record System adequate to register mental } \\
\text { health actions?* }\end{array}$ & 2.4 & 3.3 & 2.8 & 1.12 & 1.60 & 1.41 \\
\hline Collaboration between Teams & 3.2 & 3.3 & 3.3 & .52 & .57 & .54 \\
\hline Mental Health Problems & 1.6 & 1.5 & 1.6 & .38 & .21 & .32 \\
\hline Family Focus & 3.4 & 3.3 & 3.4 & .66 & .96 & .79 \\
\hline Integration with Community Resources & 2.5 & 2.7 & 2.6 & .76 & .59 & .69 \\
\hline Primary Mental Health Education & 3.4 & 3.4 & 3.4 & .90 & 1.08 & .97 \\
\hline
\end{tabular}

${ }^{*} \mathrm{M}$-W test was performed with $p$-value $<5 \%$ 
Especially noteworthy was the following contrast: Mental Health Interventions, Collaboration between Teams; Family Focus and Primary Mental Health Education received the worst evaluation by the General Traditional Outpatients and the best by the Psychosocial Community Centre. In Team Collaboration, Psychosocial Community Centre as specialised services and FHS as non-specialised services obtained very similar values $(3,6 / 5)$, which means that they considered they work collaboratively in about $70 \%$ of their cases; likewise, for Family Focus $(3,9 / 5)$, which means they believe they usually care for people using this strategy in about $80 \%$ of their cases (Table 4 ).

\section{Qualitative results}

\section{Descriptive information: structure, examples of} interventions and partnerships

Some questions had space for examples or specific information. The answers that appeared in this study are:

1. Analysis of contact resources showed that all units have an e-mail, telephone and access to the Internet.

2. Regarding Mental Health Interventions, the examples shared indicated in general a large provision of groups for patients with different health conditions, such as: chronic diseases; reducing health problems; family planning; pregnancy; adolescents; the elderly; anti-smoking; alcoholics anonymous; handicrafts; gardening; income generation; yoga and massage.

3. Regarding Integration with Community Resources, professionals mentioned as examples: outpatient units; emergency units; hospitals; university services; programmatic area coordination; health system information; nurseries; schools; "Health in the School" program; police; shelters for women, men and the elderly; non-profit organisations; football teams; samba schools; community radio and Peacemaking units.

\section{Open-ended question: positive and negative perceptions of mhms}

The open-ended question was to elicit from the interviewee their opinions about mental health and primary care integration regarding MHMS actions. Thus, these professionals were asked to share their positive and negative opinions. As the managers sample was very small, this research group analysed this answer without comparing health managers and professionals.

As a whole, the outcomes highlighted significant aspects of MHMS organisation, workforce and practice. Taking into account the different analytical themes, health professionals' perceptions were organised into three categories: Network, Primary Mental Health Education and Primary Mental Health Interventions. Communication problems emerged as a common issue in all situations related to primary care and mental health integration and they are present in all three categories.

The Network category considered how the structural components of MHMS teams are connected, including logistics, human resources, workforce, and organisational partnerships. This category highlighted issues such as networking, integration and institutional communication. For instance:

"The municipal government should constantly communicate the workflow between specialists and non-specialists because we do not know where new FHS teams are being created, what their scope is and which territory they cover". (Manager 1, outpatient specialized services psychiatrist).

Table 4 Comparing different managers' perceptions perspectives

\begin{tabular}{|c|c|c|c|c|c|c|c|c|c|c|}
\hline \multirow{3}{*}{$\begin{array}{l}\text { Managers' perception } \\
\text { Kruskall-Wallis non-parametric test (K-W) }\end{array}$} & \multicolumn{5}{|l|}{ Mean } & \multicolumn{5}{|c|}{ Std. deviation } \\
\hline & \multicolumn{5}{|c|}{ Services (Managers answers/4 groups) } & \multicolumn{5}{|c|}{ Services } \\
\hline & $\begin{array}{l}\text { GTO } \\
n=4\end{array}$ & $\begin{array}{l}\mathrm{MHOS} \\
n=4\end{array}$ & $\begin{array}{l}\text { PCC } \\
n=2\end{array}$ & $\begin{array}{l}\mathrm{FHS} \\
n=8\end{array}$ & $\begin{array}{l}\text { Total } \\
n=18\end{array}$ & GTO & MHOS & PCC & FHS & Total \\
\hline Access $^{*}$ & 3.1 & 2.4 & 3.2 & 3.2 & 3.0 & .31 & .42 & .18 & .34 & .43 \\
\hline Gateway & 3.5 & 3.5 & 3.2 & 3.8 & 3.6 & .89 & 1.11 & .27 & .59 & .74 \\
\hline Trust & 4.2 & 4.4 & 4.5 & 4.5 & 4.4 & .28 & .24 & .44 & .46 & .37 \\
\hline Mental health Interventions* & 2.1 & 3.0 & 3.8 & 2.8 & 2.8 & .37 & .56 & .05 & .48 & .63 \\
\hline Is Record System adequate to register mental health actions? & 3.3 & 4.4 & 4.0 & 2.5 & 3.3 & 1.52 & .42 & .47 & 1.91 & 1.60 \\
\hline Collaboration between Teams* & 2.6 & 3.3 & 3.7 & 3.6 & 3.3 & .37 & .47 & .49 & .39 & .57 \\
\hline Mental Health Problems* & 1.3 & 1.5 & 1.8 & 1.6 & 1.5 & .17 & .11 & .33 & .17 & .21 \\
\hline Family Focus* & 2.3 & 2.8 & 4.0 & 3.9 & 3.3 & .63 & .35 & .00 & .86 & .96 \\
\hline Integration with Community Resources & 2.6 & 2.6 & 3.0 & 2.8 & 2.7 & .43 & .94 & .24 & .58 & .59 \\
\hline Primary Mental health Education* & 2.3 & 3.0 & 4.7 & 3.9 & 3.4 & 1.20 & .72 & .47 & .71 & 1.08 \\
\hline
\end{tabular}

*K-W test was performed with $p$-value $<5 \%$ 
This quotation illustrates the lack of knowledge about different systems' structures and how that can negatively affect the interactions between different services. On the other hand, the quotation below demonstrates how positive the network can be when the partnership between services is clear.

\section{(...) when we have this strong partnership, we access a} mental health support team, doing referrals and counter referrals, leading to better understanding of the case for planning care". (Manager 1)

The Primary Mental Health Education category referred to the relevance of integrating knowledge and expertise between different workforces. Not only is it suggested that health professionals need to learn from each other, but also that different work processes must be integrated and further knowledge may be acquired by all the professionals involved. For example:

\section{“(..) patients already exist, but we need (as primary care professionals) to better understand what it is possible to do in order to offer support to them here, because it is so difficult to work with mental health problems.” (Manager 2, FHS, nurse)}

This quotation highlighted how difficult it is for a non-specialist to care for mental health problems without tools or enough knowledge to tackle these problems, including the capacity to recognise mental health problems. Similarly, this same quotation showed that the professional considers it important to receive technical support to be able to help patients with this type of problem.

"The problem is the lack of human resources, because all that (regarding the health system changes in the city) will raise demand, and unfortunately we cannot address current problems". (Manager 3, GTO, doctor)

Concerning Primary Mental Health Education, while the previous quotation emphasised human resources availability, the following quotation demonstrated a concern with the quality of primary mental health education when the interviewee described the relevance of MHMS to improve community health workers' capacity to deal with mental health problems, mainly because they are considered gatekeepers of the health system.

"MHMS have been qualifying community health workers. MHMS organised training sessions for their work (mentioning community health workers)".

(Health professional 1, FHS, GP)
Furthermore, as well as showing an improvement in the capacity to identify and treat mental health problems, the next quotation underlines that FHS teams should understand, in technical terms, the primary mental health professional's conceptual references.

\section{(...) but I do not know if people know that we need a methodology concerning MHMS teams' references, something more formal, a structured methodology, (...). (health professional 2. FHS, GP).}

The Primary Mental Health Intervention category is concerned with how mental health actions in primary care have been delivered. The actions mentioned were: MHMS, support for the FHS team, prevention and mental health promotion, implementation of community therapy, home visits and joint consultations.

Positive evaluations included a clinical perspective of the primary care professionals when referring to the consequences of the integration.

\section{"I think that we have been improving diagnosis and treatment of mental illnesses". (Health Professional, FHS, GP2)}

Moreover, primary mental health care interventions were considered important as professionals search for better understanding and to act closer to the patients' context than was done in a traditional specialised mental health approach, as it usually focused on the individual's disease only.

"Mental health patients should be cared for in their area, with people they trust, in their home environment, in their territory". (Health Professional, FHS, GP1)

From a negative perspective, the general timetable was the main issue.

"The problem with the matrix support is it takes place once a month, when we have many more patients that must be treated more frequently". (Manager, FHS, nurse)

This quotation not only demonstrates difficulties related to the integration of different work processes but also emphasises a concern with the continuity of mental health care, which is one of MHMS teams' biggest challenges.

The table below summarises the main qualitative data findings, showing positive aspects as benefits and negative aspects as barriers to integrating mental health and primary care (Table 5). 
Table 5 Open-ended question summary

\begin{tabular}{|c|c|c|}
\hline $\begin{array}{l}\text { Mental Health and } \\
\text { Primary Care Integration }\end{array}$ & Positive aspects & Negative aspects \\
\hline Network category & $\begin{array}{l}\text { - Connecting primary care and mental health services. } \\
\text { - Planning care together }\end{array}$ & $\begin{array}{l}\text { - Lack of knowledge about different units, system } \\
\text { structures and work processes } \\
\text { - Constraints regarding institutional processes }\end{array}$ \\
\hline $\begin{array}{l}\text { Primary Mental Health } \\
\text { education category }\end{array}$ & $\begin{array}{l}\text { - Helping non-specialists managing mental health problems } \\
\text { - Training SUS gatekeepers to identify mental health problems } \\
\text { - Narrowing the communication gap between different } \\
\text { work processes } \\
\text { - Favouring primary teams to diagnose and prescribe } \\
\text { appropriate interventions. }\end{array}$ & $\begin{array}{l}\text { - Lack of human resources, excessive turnover of GPs, } \\
\text { excessive working hours } \\
\text { - Lack of knowledge regarding psychosocial interventions } \\
\text { in PC }\end{array}$ \\
\hline $\begin{array}{l}\text { Primary Mental Health } \\
\text { Interventions category }\end{array}$ & $\begin{array}{l}\text { - Improving access to cases of difficult adherence } \\
\text { - Delivering mental health care in the community } \\
\text { - Integrating actions to care of co-morbidities }\end{array}$ & $\begin{array}{l}\text { - Integrating different professionals' timetables } \\
\text { - Low frequency of mental health matrix support in the } \\
\text { community (once a month) } \\
\text { - Continuity of care is not perceived as a health tenet }\end{array}$ \\
\hline
\end{tabular}

\section{Mixed-method results}

Faced with these results and using the 3 key issues in a framework, this study linked crucial points between the methods. Thereby, the outcomes were:

i) What are the health professionals' perceptions about MHMS in Rio during the period studied?

The quantitative results showed that the professionals interviewed have been evaluating their actions only based on recent experiences or discussions. The qualitative results demonstrated that the workforce's experiences pointed to challenges and difficulties to integrate different work processes, considering perceptions and experiences without clear and structured references.

ii) What are the similarities and differences between health managers' and professionals' perceptions?

While quantitative data showed that health managers and professionals had different perspectives only of the record system of this evaluation, qualitative data demonstrated the importance for both groups of clear communication, good relationships with other institutions and continuing primary mental health education to create a network and integrate actions from different perspectives. This shows how difficult it can be to integrate different work processes in a context where communication is problematic.

iii) What prospects are there for Brazilian MHMS?

Quantitative data about health managers and professionals demonstrated that these professionals converge in most of their perceptions. However, quantitative data about managers' perceptions of service design contrasted different perspectives from traditional services and community-based services. The qualitative results emphasise how important it is to consider institutional designs to foster integration between different services without support or specific knowledge.

\section{Discussion}

Evaluating primary care and mental health integration was planned as a local demonstrative project, exploring the perceptions of professionals involved in integrated care to offer primary mental health care to a low-income population, especially in community-based contexts. The main findings were:

1. The need for the creation of an instrument to evaluate the perception of professionals involved in $\mathrm{PC}$ and $\mathrm{MH}$ integration actions. The points of the questionnaire referred to the structure of the health system, the method of work between the professionals and the method of work to offer primary mental health care.

2. Health managers' and professionals' perceptions tend to agree in all points studied, except for Health Record System.

3. Managers' perceptions of service design tend to disagree on points such as Access, Mental Health Interventions, Team Collaboration, Family Focus and Primary Mental Health Education. These perceptions tend to agree in terms of Gateway, Trust, Record System and Integration with Community Resources and Primary Mental Health Education.

4. A lack of communication and clear common knowledge about MHMS were underscored as crucial problems.

5. The mixed method demonstrated how important it is to contrast information concerning workforce and institutional perceptions faced with positive and negative MHMS aspects. 
6. Health managers and professionals consider mental health and primary care integration as a requirement of the system.

These findings confirmed that planning and managing the integration of different work processes are fundamental to understanding the workforce's point of view as well as to understanding they are strongly influenced by the model of work produced by the institutional culture [58]. For instance, these professionals value Primary Mental Health Education (3.4/5), and they are looking forward to improving their skills and knowledge to deliver mental health actions in Rio de Janeiro's favelas, as the Primary Mental Health category highlighted. However, the workforce interviewed demonstrated awareness of constraints in institutional processes, human resources and knowledge [59]. These negative aspects suggest that despite health professionals' being open and agreeing to work with MHMS, infrastructure problems have been identified in this vulnerable, low-income [60] and violent area, revealing inconsistencies between workforce and institutional perspectives.

Regarding the MHGAP, there was an interesting comparison of this setting with research in countries undergoing socio-economic conflicts and also wars in LAMIC. The literature review showed that although it is possible to facilitate primary care and mental health integration [61], indicators such as governance and different workforces [62] are better managed regionally [63], in the same health level platforms as in national perspectives, with different levels of health involved. Moreover, primary mental health care is, in some cases, considered a humanitarian solution, delivering health care to vulnerable people [64].

Nowadays, similar experiences of MHMS, as in Rio de Janeiro's favelas, are growing in many Brazilian cities as a political strategy to improve the capacity of FHS teams to treat and prevent health problems and promote community-based health. This nationwide perspective has been implemented through Multidisciplinary Matrix support teams, where the presence of a mental health professional is always guaranteed [24]. This is especially important considering that Brazil is a country with more than 5000 municipalities, where this process is being massively implemented. However, as the findings emphasised, two different primary care platforms and a lack of clear information revealed a lack of common and clear objectives shared with this workforce [58].

For example, the evidence about the information recorders not only highlighted the relevance of an integrated information system but also these perceptions showed the concerns of these health professionals about how their work can be measured.
Another interesting example of a difference in viewpoints was that community-based health managers (PCC and FHS) evaluated better the sections on the community-based method of work, whereas the health managers working in traditional services evaluated them as worse. In order to integrate primary care and mental health it is important to recognise whether or not the MHMS purposes are coherent with health service culture to unite two different work processes. Hence, the need to create a programme integrating mental health into primary care in order to deliver primary mental health care and overcome the MHgap [27, 65].

These findings offer an insight into how primary mental health teams have experienced MHMS, suggesting that now is the time to qualify these actions [14], empower the workforce [5] and improve the network's capability [66].

Likewise, especially noteworthy was the gap between work processes and expertise for the development of MHMS. These outcomes confirm the existence of subjective barriers in institutional relationships [23] and suggest that lack of communication might be responsible for points of tension between those involved, such as technical and ideological differences.

For example, in severe mental health cases, the collaboration between PCC and primary care services only happens when PCC patients need it and not when communitybased primary care services identify the need of specialised collaboration in its area. This point may underline how important the link is between the need for institutional support and improved communication [14, 22, 67, 68].

Thus, the data identified some differences between health professionals as points of tension. For instance, even when the professional has a positive experience with MHMS, the qualitative data emphasised how difficult it is to combine two different backgrounds, sharing knowledge and making decisions together.

For further initiatives, explanatory guidelines, websites and telehealth might be important as a form of professional health education. Moreover, the creation of specific national primary mental health care indicators to evaluate these health services and practices is important to organise the primary mental health agenda [66], particularly considering the continuity of mental health care in primary care [69].

Some strengths of this study were:

- Contributing to the literature about primary care and community-based mental health integration in Brazil, Latin America and LAMIC;

- Integrating quali-quanti data such as health managers' and professionals' perceptions, health managers' perceptions of different services involved in PC and $\mathrm{MH}$ and MHMS opinions in a mixedmethods study; 
- Emphasising the association of health professionals' workforce and institutional designs in public health as a fundamental issue to think about health services and research.

\section{The limitations were:}

- The number of interviewees was small, which suggests the need for further studies with a similar methodology in other areas of the city and the country;

- Data collection was done in two different periods. It would have been preferable to collect it all in the same period and a few questionnaire questions lack specificity in terms of mental health references or primary care;

- We did not interview important members of FHS teams such as nurses and community workers. This study also did not sufficiently evaluate long-term outcomes and was primarily aimed at doctors (GPs, psychiatrists and psychologists).

\section{Conclusion}

The aim of this study was to map health managers' and professionals' perceptions about Primary Care and Mental Health by MHMS in Rio de Janeiro. The lessons learnt were especially about how to plan actions to deliver primary mental health care in vulnerable communities.

Although SUS is unified, this system has two primary care platforms in activity. The complexity of this background along with the findings concerning the record system suggests it is essential to integrate and record the available information about the integration process in a common health record system. This clearly demonstrates the reach and impact of primary mental health actions in the communities and how they can differ from traditional services.

These perceptions provided valuable lessons for policy planning and research, including aspects related to those points of tension where different perspectives on mental health care must be integrated. This involves engaging the policy makers, managers, primary care and mental health professionals on the ground. Hence, the study pointed to the challenge of connecting different health knowledge and the importance of communication strategies.

Additionally, health professionals clearly recognised the need to improve their knowledge about primary mental health care, underlining willingness on their part to rethink their actions. However, they need institutional support and motivation to be involved in further actions.

Concluding, in order to push the boundaries of traditional mental health interventions as a means of delivering mental health care in the community, not only did this study reveal that enhancing institutional communication is essential to integrate different work processes but it also shows that health professionals should be turned into stakeholders.

\section{Endnotes}

${ }^{1}$ From this explanation on referred to the Brazilian National Health Service simply as SUS.

${ }^{2}$ Grupo Interdisciplinar de Pesquisa em Atenção Primária à Saúde-CNPq (Conselho Nacional de Desenv olvimento Científico) (http://dgp.cnpq.br/dgp/espelhogru po/9879901048555185).

\section{Additional file}

Additional file 1: Questionnaire Mapping the Integration of Mental Health Interventions in Primary Care. This questionnaire was originally in Portuguese. The English version was based on the original, considering only the items discussed in this original paper. (DOC $180 \mathrm{~kb}$ )

\section{Abbreviations \\ FHS: Family Health Strategy; GTO: General Traditional Outpatient; HDI: Human Development Index; LAMIC: Low and middle income countries; MH: Mental Health; MHGAP: Mental Health Gap; MHMS: Mental Health Matrix Support; MHOS: Mental Health Outpatient Services; PC: Primary Care; PCC: Psychosocial Community Centre; SDI: Social Development Index; SUS: Unified Health System; WHO: World Health Organization}

\section{Acknowledgements}

We sincerely thank Prof. Cesar Favoretto and Stella Taquete for their altruistic contributions and the interviewees for sharing their perceptions about their process of work. Additionally, we would like to thank Mr. Robin Ward for improving the language of this paper. And finally, we offer our thanks to the institutional support of Medical Sciences Post-Graduation Program of University of the State of Rio de Janeiro; CAPES; CNPq; Secretarial Municipal de Saude e Defesa Civil da Cidade do Rio de Janeiro; and the Institute of Psychology Health and Society-University of Liverpool.

\section{Funding}

This study has received funding support from FAPERJ (Fundação de Amparo à Pesquisa do Estado do Rio de Janeiro) and CAPES (Comissão de Aperfeiçoamento de Pessoal do Nível Superior), who sponsored my doctoral sandwich in the University of Liverpool.

\section{Availability of data and materials}

The datasets generated during and/or analysed during the current study are not publicly available as they contain interviewees' identifiable information. Sharing data would breach interviewee confidentiality.

\section{Authors' contributions}

KA conceived the study and drafted the manuscript, including data acquisition, analysis and interpretation, in addition to the final revision. She has given final approval of the version to be published and agreed to be accountable for all aspects of the work in ensuring that questions related to the accuracy or integrity of any part of the work have been appropriately investigated and resolved. AM interviewed professionals for data collection, proofreading, and revising. AMdS interviewed professionals for data collection, proofread and revised. MRC participated in the design of the study and performed the statistical analysis, interpretation of data and revision. PGD conceived the study and participated in its design, making corrections on the final version. SF conceived the study and participated in its design and coordination, helped to draft the manuscript and agreed to be accountable for all aspects of the work in ensuring that questions related to the accuracy or integrity of any part of the work have been appropriately investigated and resolved. CD helped to draft the manuscript, has given final approval of the version to be published and agreed to be accountable for all aspects of the work in ensuring that questions related to the accuracy or 
integrity of any part of the work have been appropriately investigated and resolved. The publication of this paper has been approved by all co-authors.

\section{Competing interests}

This study does not have financial, political, personal, religious, ideological, academic, intellectual, commercial or any other competing interests.

\section{Consent for publication}

Not applicable.

\section{Ethics approval and consent to participate}

The research protocol was approved by the University of the State of Rio de Janeiro and by the Municipal Secretary of Health for the City of Rio de Janeiro Ethics Research Committees (CAAE n.0.:0252.0.314.000-10). All participants signed an informed written consent approved by the ethics committee.

\section{Author details}

1Programa de Pós Graduação em Ciências Médicas/ Faculdade de Ciências Médicas, Universidade do Estado do Rio de Janeiro, Rio de Janeiro, Brazil. ${ }^{2}$ Laboratório Interdisciplinar em Atenção Primária à Saúde/LIPAPS/Faculdade de Ciências Médicas, Universidade do Estado do Rio de Janeiro, Rio de Janeiro, Brazil. ${ }^{3}$ Escola Nacional de Saúde Pública, Fundação Oswaldo Cruz, Rio de Janeiro, Brazil. ${ }^{4}$ Núcleo de Pesquisas em Políticas Públicas de Saúde Mental/ Instituto de Psiquiatria da Universidade do Brasil, Universidade Federal do Rio de Janeiro, Rio de Janeiro, Brazil. ${ }^{5}$ Institute of Psychology Health and Society, University of Liverpool, Liverpool, UK.

\section{Received: 15 December 2015 Accepted: 6 September 2016}

\section{Published online: 30 September 2016}

\section{References}

1. Kakuma R, Minas H, van Ginneken N, Dal Poz MR, Desiraju K, Morris JE, et al. Global Mental Health 5 Human resources for mental health care: current situation and strategies for action. Lancet. 2011;378(9803):1654-63.

2. World Health Organization. mhGAP intervention guide - For mental, neurological and substance abuse disorders in non-specialized health settings [Internet]. Mental Health Gap Action Programme. Geneva; 2010.

3. Hailemariam M, Fekadu A, Selamu M, Alem A, Medhin G, Giorgis TW, et al. Developing a mental health care plan in a low resource setting: the theory of change approach. BMC Health Serv Res. 2015;15(1):429.

4. Zolnierek CD. Mental health policy and integrated care: global perspectives. J Psychiatr Ment Heal Nurs. 2008;15(7):562-8.

5. Sunkel C. Empowerment and partnership in mental health. Lancet. 2012;379(9812):201-2.

6. Chisholm D, Flisher AJ, Lund C, Patel V, Saxena S, Thornicroft G, et al. Scale up services for mental disorders: a call for action. Lancet [Internet]. 2007;370(9594):1241-52. Elsevier; [cited 2015 Nov 2].

7. World Health Organization (WHO), WHO and WONCA, Vingilis $\mathrm{E}_{\text {, }}$ Paquette-Warren J, Kates N, Crustolo AM, et al. Collaborative Care: models for treatment of patients with complex medical-psychiatric conditions. UNESCO e Ministério da Saúde, editor. Ciênc saúde coletiva [Internet]. BMC Health Serv Res. 2013;4(1):473-4 [cited 2014 May 2].

8. Starfield B, Shi L, Macinko J. Contribution of primary care to health systems and health. Milbank Q. 2005;83(3):457-502.

9. Patel V. Mental health in low- and middle-income countries. Br Med Bull. 2007;81-82(1):81-96 [cited 2015 Oct 30].

10. Conill EM. [Primary care policies and health reforms: an evaluative approach based on an analysis of the Family Health Program in Florianopolis, Santa Catarina, Brazil, 1994-2000]. Cad Saude Publica. 2002;18(Suppl):191-202.

11. Nunes MA, Ferri CP, Manzolli P, Soares RM, Drehmer M, Buss C, et al. Nutrition, mental health and violence: from pregnancy to postpartum Cohort of women attending primary care units in Southern Brazil-ECCAGE study. BMC Psychiatry. 2010;10:66.

12. Taborda JG, Bertolote JM, Cardoso RG, Blank P. The impact of primary mental health care in a prison system in Brazil. Can J Psychiatry. 1999:44(2):180-2.

13. Paula CS, Nakamura E, Wissow L, Bordin I a, do Nascimento R, Leite AM, et al. Primary care and children's mental health in Brazil. Acad Pediatr. 2009;9(4):249-55.e1.
14. Goncalves DA, Fortes S, Campos M, Ballester D, Portugal FB, Tófoli LF, et al. Evaluation of a mental health training intervention for multidisciplinary teams in primary care in Brazil: a pre- and posttest study. Gen Hosp Psychiatry. 2013;35(3):304-8.

15. Frosi RV, Tesser CD. Mental health care practices in primary health care: an analysis based on experiences developed in Florianópolis, Brazil. Cien Saude Colet [Internet]. 2015;20(10):3151-61 ABRASCO - Associação Brasileira de Saúde Coletiva; [cited 2015 Oct 30].

16. Goncalves DA, Fortes S, Tofoli LF, Campos MR, Mari Jde J. Determinants of common mental disorders detection by general practitioners in primary health care in Brazil. Int J Psychiatry Med. 2011:41(1):3-13.

17. Kathree T, Selohilwe OM, Bhana A, Petersen I. Perceptions of postnatal depression and health care needs in a South African sample: the "mental" in maternal health care. BMC Womens Health. 2014;14(1):140.

18. de Jesus Mari J, Tófoli LF, Noto C, Li LM, Diehl A, Claudino AM, et al. Pharmacological and psychosocial management of mental, neurological and substance use disorders in low- and middle-income countries: issues and current strategies. Drugs. 2013;73:1549-68. Available from: http://www. ncbi.nlm.nih.gov/pubmed/24000001.

19. Knowles SE, Chew-Graham C, Coupe N, Adeyemi I, Keyworth C, Thampy H, et al. Better together? a naturalistic qualitative study of inter-professional working in collaborative care for co-morbid depression and physical health problems. Implement Sci. 2013;8(1):110. Available from: http://www. implementationscience.com/content/8/1/110.

20. Lawn S, Lloyd A, King A, Sweet L, Gum L. Integration of primary health services: being put together does not mean they will work together. BMC Res Notes. 2014;7:66.

21. Bower P. Primary care mental health workers: models of working and evidence of effectiveness. Br J Gen Pract. 2002;52(484):926-33.

22. Campbell SM, Shield T, Rogers A, Gask L. How do stakeholder groups vary in a Delphi technique about primary mental health care and what factors influence their ratings? Qual Saf Health Care. 2004;13(March 2008):428-34.

23. Gask L. Overt and covert barriers to the integration of primary and specialist mental health care. Soc Sci Med. 2005;61:1785-94.

24. Macinko J, Harris MJ. Brazil's family health strategy - delivering community-based primary care in a Universal Health System. N Engl J Med. 2015;372(23):2177-81.

25. Gonçalves DA, Mari Jde J, Bower P, Gask L, Dowrick C, Tófoli LF, et al. Brazilian multicentre study of common mental disorders in primary care: rates and related social and demographic factors. Cad Saude Publica [Internet]. 2014;30(3):623-32 Escola Nacional de Saúde Pública, Fundação Oswaldo Cruz; [cited 2015 Jul 10].

26. Portugal FB, Campos MR, Gonçalves DA, Mari JDJ, Gask L, Bower P, et al. Psychiatric morbidity and quality of life of primary care attenders in two cities in Brazil. J Bras Psiquiatr. 2014;63(1):23-32.

27. Mateus MD, Mari JJ, Delgado PGG, Almeida-Filho N, Barrett T, Gerolin J, et al. The mental health system in Brazil: Policies and future challenges. Int J Ment Health Syst. 2008;2(1):12.

28. Harzheim E, Lima KM, Hauser L. Pesquisa avaliativa sobre aspectos de implantacao, estrutura, processo e resultados das clinicas da familia na cidade do Rio de Janeiro [Internet]. Porto Alegre: Universidade Federal do Rio Grande do Sul (UFRGS); 2013.

29. Do Patrocínio SSM, et al. The Support Center for Family Health: national proposal and implementation in towns of Rio de Janeiro. Saúde debate Vol 39 no spe Rio de Janeiro; 2015.

30. Xavier HN, Magalhães F. Urban Slums Reports: The case of Rio de Janeiro, Brazil [Internet]. Urban Slums Reports. Rio de Janeiro; 2003. Available from: http://www.ucl.ac.uk/dpu-projects/Global_Report/pdfs/Rio_bw.pdf. Accessed 12 Sept 2016

31. Gaffney C. Mega-events and socio-spatial dynamics in Rio de Janeiro, 1919-2016. J Lat Am Geogr. 2010;9(1):7-29.

32. Roth-Gordon J. The language that came down the hill: Slang, crime, and citizenship in Rio de Janeiro. Am Anthropol. 2009;111(1):57-68.

33. Instituto Municipal de Urbanismo Pereira Passos (Armazém dos dados). Índice de Desenvolvimento Social (IDS) e seus indicadores constituintes, segundo favelas. Rio de Janeiro: Prefeitura do Rio de Janeiro; 2010.

34. Instituto Municipal de Urbanismo Pereira Passos (Armazém dos dados). Indicadores de Renda - Desigualdade por extratos da população. Renda domiciliar nominal per capita média do $1^{\circ}, 2^{\circ}, 3^{\circ}, 4^{\circ}$ e $5^{\circ}$ quintos mais pobres e do quinto e décimo mais ricos, por Bairros ou Grupo de Bairros. Rio de Janeiro: Prefeitura do Rio de Janeiro; 2010. 
35. Instituto Municipal de Urbanismo Pereira Passos (Armazém dos dados). Desenvolvimento Humano e Condições de Vida na Cidade do Rio de Janeiro (jan. 2004) (Estudo N 1347) [Internet]. Rio de Janeiro; 2004. Available from: http://www.camara.rj.gov.br/planodiretor/pd2009/saudepd/ Anexo3_IDH.pdf. Accessed 12 Sept 2016.

36. Prefeitura do Rio de Janeiro. Instituto Municipal de Urbanismo Pereira Passos (Armazém dos dados) [Internet]. 2000 [cited 2015 Nov 20]. Available from: http://www.armazemdedados.rio.rj.gov.br/. Accessed 12 Sept 2016

37. Governo do Rio de Janeiro. Unidade de Policia Pacificadora website [Internet]. [cited 2015 Nov 20]. Available from: http://www.upprj.com/. Accessed 12 Sept 2016.

38. Simon GE, Katon WJ, VonKorff M, Unutzer J, Lin EH, Walker EA, et al. Costeffectiveness of a collaborative care program for primary care patients with persistent depression. Am J Psychiatry. 2001;158(10):1638-44.

39. Gilbody S, Bower P, Fletcher J, Richards D, Sutton AJ. Collaborative care for depression: a cumulative meta-analysis and review of longer-term outcomes. Arch Intern Med. 2006;166(21):2314-21.

40. Bower P, Gilbody S, Richards D, Fletcher J, Sutton A. Collaborative care for depression in primary care. Making sense of a complex intervention: systematic review and meta-regression. Br J Psychiatry. 2006:189:484-93.

41. Chiaverini D. Guia Prático de Matriciamento em Saúde Mental. Brasília: Ministério da Saúde; 2011.

42. Prefeitura do Rio de Janeiro. Plano Municipal de Saúde do Rio de Janeiro PMS [Internet]. 2014. Available from: http://www.rio.rj.gov.br/dlstatic/10112/ 3700816/4128745/PMS_20142017.pdf. Acessed 12 Sept 2016.

43. Friedman DJ, Starfield B. Models of Population Health: their value for US Public Health Practice, policy, and research. Am J Public Health. 2003;93(3):366-9.

44. Haggerty JL, Reid RJ, Freeman GK, Starfield BH, Adair CE, McKendry R. Continuity of care: a multidisciplinary review. BMJ Br Med J. 2003:327(7425):1219-21.

45. Ministério da Saúde. Manual do instrumento de avaliação da Atenção Primária à Saúde. 2010. p. 80

46. Blanco MN, Taquette SR, Monteiro DLM, Miranda FRD. Postnatal and postabortion care during adolescence in the National Health System in Rio de Janeiro, Brazil. Int J Gynecol Obstet. 2014;126(2):126-9.

47. Cronbach L. Coefficient alpha and teh internal structure of tests. Psychometrika. 1951;16(3):297-334.

48. Taft C, Karlsson J, Sullivan M. Performance of the Swedish SF-36 version 2.0. Qual Life Res. 2004;13(1):251-6.

49. George D. SPSS for Windows step by step: A simple guide and reference. 11.0 update [Internet]. Boston: Allyn y Bacon; 2003. p. 386.

50. Snape D, Spencer $L$. The foundation of qualitative research. In: Editoral matter, editor. Qualitative research practice: A guide for social science students and researchers. London: SAGE Publications; 2003. p. 2-10.

51. Thomas J, Harden A. Methods for the thematic synthesis of qualitative research in systematic reviews. BMC Med Res Methodol. 2008:8:45

52. Jenkins R, Othieno C, Okeyo S, Aruwa J, Kingora J, Jenkins B, et al. Health system challenges to integration of mental health delivery in primary care in Kenyaperspectives of primary care health workers. BMC Health Serv Res. 2013;13:1.

53. Siriwardhana C, Adikari A, Jayaweera K, Abeyrathna B, Sumathipala A. Integrating mental health into primary care for post-conflict populations: a pilot study. Int J Ment Health Syst. 2016;10(1):12.

54. Thomas DR. A general inductive approach for qualitative data analysis. Popul English Ed. 2003;27(2):237-46.

55. Cathain AO, Murphy E, Nicholl J. Three techniques for integrating data in mixed methods studies. BMJ. 2010;341(November):1147-50.

56. O'Cathain A, Murphy E, Nicholl J. RESEARCH METHODS \& REPORTING: Three techniques for integrating data in mixed methods studies. BMJ Br Med J. 2010:341:1147-50. Overseas Retired Dr Ed.

57. Chew-Graham C, et al. Aiming to improve the quality of primary mental health care: developing an intervention for underserved communities. BMC Family Practice. 2014;15:68

58. Warne T, McAndrew S, King M, Holland K. Learning to listen to the organisational rhetoric of primary health and social care integration. Nurse Educ Today. 2007:27(8):947-54.

59. Ford K, Middleton J, Palmer B, Farrington A. Primary healthcare workers: training needs in mental health. Br J Nurs [Internet]. 2014;6(21):1244-50. MA Healthcare London; [cited 2015 Jul 17].
60. Patel V, Araya R, De Lima M, Ludermir A, Todd C. Women, poverty and common mental disorders in four restructuring societies. Soc Sci Med. 1999;49(11):1461-71.

61. Jenkins R, Bobyleva Z, Goldberg D, Gask L, Zacroeva AG, Potasheva A, et al. Integrating mental health into primary care in Sverdlovsk. Ment Health Fam Med. 2009;6:29-36. Radcliffe Publishing.

62. Majale M. Employment creation through participatory urban planning and slum upgrading: The case of Kitale, Kenya. Habitat Int. 2008;32:270-82.

63. O'Hanlon KP, Budosan B. Post-disaster recovery: a case study of human resource deployment in the health sector in post-conflict Kosovo. Prehosp Disaster Med. 2011;26(1):7-14.

64. Kelly JT, Betancourt TS, Mukwege D, Lipton R, VanRooyen MJ. Experiences of female survivors of sexual violence in eastern Democratic Republic of the Congo: a mixed-methods study. Confl Health. 2011;5(1):25. Available from: http://www.conflictandhealth.com/content/5/1/25.

65. Bruckner TA, Scheffler RM, Shen G, Yoon J, Chisholm D, Morris J, et al. The mental health workforce gap in low- and middle-income countries: A needs-based approach. Bull World Health Organ. 2011;89(3):184-94.

66. Coupe N, Anderson E, Gask L, Sykes P, Richards DA, Chew-Graham C. Facilitating professional liaison in collaborative care for depression in UK primary care; a qualitative study utilising normalisation process theory. BMC Fam Pract. 2014;15(1):78

67. Flys T, González R, Sued O, Suarez Conejero J, Kestler E, Sosa N, et al. A novel educational strategy targeting health care workers in underserved communities in Central America to Integrate HIV into primary medical care. PLOS One. 2012:7(10):e46426.

68. King M, Nazareth I, Lampe F, Bower P, Chandler M, Morou M, et al. Conceptual framework and systematic review of the effects of participants' and professionals' preferences in randomised controlled trials. Winchester: Health technology assessment; 2005.

69. Belling R, Whittock M, McLaren S, Burns T, Catty J, Jones IR, et al. Achieving continuity of care: facilitators and barriers in community mental health teams. Implement Sci. 2011:6(1):23.

\section{Submit your next manuscript to BioMed Central and we will help you at every step:}

- We accept pre-submission inquiries

- Our selector tool helps you to find the most relevant journal

- We provide round the clock customer support

- Convenient online submission

- Thorough peer review

- Inclusion in PubMed and all major indexing services

- Maximum visibility for your research

Submit your manuscript at www.biomedcentral.com/submit
) Biomed Central 